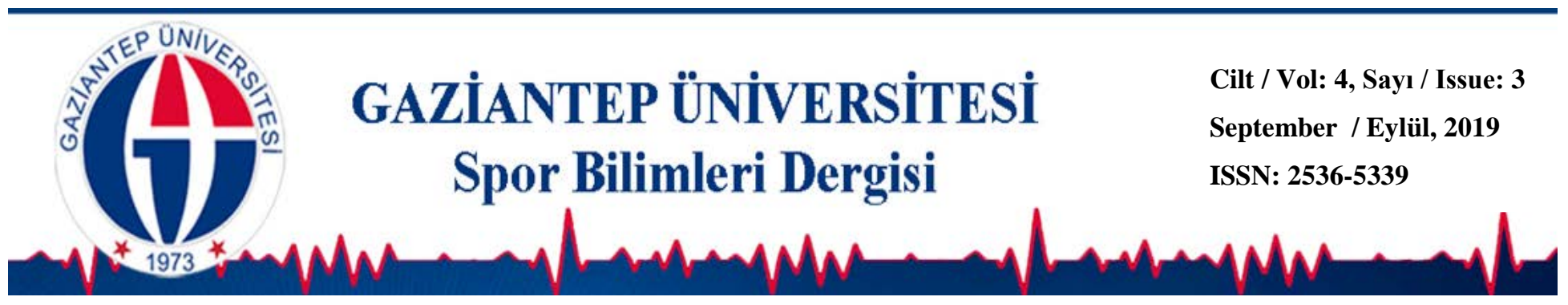

\title{
2018 Fifa Dünya Kupası Şampiyonu Fransa Milli Takımının Başarı Analizi
}

\author{
Alper KARTAL ${ }^{1 *}$ iD \\ Esin ERGIN ${ }^{1}$ \\ ${ }^{1}$ Adnan Menderes Üniversitesi, Spor Bilimleri Fakültesi, AYDIN
}

DOI: 10.31680/gaunjss.577384

Orijinal Makale / Original Article

Geliş Tarihi / Received: 13.06.2019

Kabul Tarihi / Accepted: 06.09.2019

Yayın Tarihi / Published: 22.09.2019

\begin{abstract}
Öz
$\mathrm{Bu}$ çalışmada, son dünya kupası şampiyonu Fransa milli takımının şampiyonluk başarısının farklı değişkenler açısından analiz edilmesi amaçlanmıştır. Fransa milli takımının araştırma verileri, WyScout futbol analiz internet sitesinden elde edilmiştir. Maçlarda, atılan toplam şut, başarılı pas, öne pas, başarılı öne pas, isabetli şut, atılan gollerin zaman dilimine göre dağıımı, uzun pas, korner atışı, kanatlardan hücum tehlike düzeyleri, takım boyu, futbolcular arasında yapılan en sık pas kombinasyonları ve top hakimiyeti gibi parametreler ele alınıp analiz edilmiştir. Elde edilen veriler SPSS (20.0) programında kaydedilmiştir, frekans yüzde değerleri ve korelasyon hesaplanarak yorumlanmıştır. Şampiyon Fransa Milli takımının attığı gollerin \%66,6'sını ilk yarıda atarken gollerin \%50'sini 31-45. dakikalar arasında atmıştır. Fransa turnuva boyunca 77 tane şut atarken bunların 29 tanesi isabetli olmuştur ve \%37,66'lık bir başarı oranı sağlamıştır. Turnuva da Fransa Milli takımının başarılı pas oranı \%84,93'tür, başarılı ileri pas oranı ise \%74,35'dir. Fransa Milli takımının turnuva boyunca maksimum top hakimiyet süresi \%66'lık bir orandır ve takım boyu ortalaması 42,57 metredir. Fransa Milli takımının yüksek pas oranı, şut oranı, olumlu pas yüzdesi ve takım boyundaki yakınlık şampiyonluğun oluşumunda önemli olduğu düşünülmektedir. Sonuç olarak; önemli turnuvalarda, başarılı olabilmek için gerekli pek çok unsuru Fransa Milli takımının yüksek oranda yaptığı söylenebilir.
\end{abstract}

Anahtar Kelimeler: Fransa, maç analizi, futbol, performans

\section{Success Analysis of the Champion France National Team in 2018 World Cup}

\begin{abstract}
The aim of this study is to success analyze 2018 Fifa World Cup Champion France National Team. In this research data analyzed were refered from WyScout analyze internet website. Parameters on the game such as shots, success shots, total shots, success pass, front pas, accurate pass, hit shots, team lenght, most pass combination between players, ball possesion percentage were analyzed. Statistics were registered SPSS program, percentages and frequencies were calculated. Champion France National Team on the tournument has scored 14 goals and \%66.6 percentage that scores first half with \%05 percentage between 31-45 minutes. For all tournament France National Team has total 77 shots. On the tournament Maximum ball possesion for France National team had \%66 percentage and team accurate pass percentage has $\% 84,93$ percentage, front pass percentage was $\% 74,35$, team lenght average was 42,57 meter. It is being thought that, the high percentage rate of passing, shooting, accurative passing and the closing team length is vital in concering the championship. As a result, it can be said that, to be successed in the vital tournaments, France national team has done highly rated in such items.
\end{abstract}

Key Words: France, match analyses, soccer, performance

\footnotetext{
* Sorumlu Yazar: Alper KARTAL
}

E-mail: alper_kartal@hotmail.com 


\section{Giriş}

Futbol gibi mücadele gerektiren sporlarda sporcuların performans seviyeleri ve takımların başarı düzeyleri belirli kriterlere bağlılık göstermektedir. Bu kriterler sporcunun yeteneği ve tekniği dışında motivasyon, taktik anlayış, antrenman, fizik durumu ve istatistiksel verilerin futbolculara doğru aktarılmasına bağlıdır (Baskaya ve ark. 2017). Futbolcuların başarılı olmalarını sağlayan ilk önemli faktör fiziksel uygunluk ve motor özellikler gibi görülse de teknik ve taktik anlayışta ki başarı da performansı etkileyen unsurlardan biridir (Cerrah ve ark. 2016). Futbolda skor performansa bağlı olarak her an değişiklik gösterebilir, bu nedenle antrenörler oyunun her anına, değişen taktikler sebebiyle tam anlamıyla hâkim olmalıdırlar (İnce ve ark 2018). Futbol antrenörleri rakip takımdaki futbolcuların özelliklerini en az kendi takımındaki oyuncular kadar iyi bilmelidir oyuncuların güçlü yanları, zayıf yanları ve tabii ki takımların genel olarak güçlü ve zayıf yanlarını da bilmelidirler. Bu nedenle video analiz uygulamaları ve istatistiksel veriler futbolda oldukça fazla önem arz etmektedir (Michailidis ve ark. 2013). Futbol müsabakalarının analizi konusu son dönemlerde üzerinde çok konuşulan ve araştırmalar yapılan bir konudur. Genelde futbolda büyük organizasyonlardan sonra, başarılı takımların oyun sistemleri, oyun tarzları ve oyuncuların bireysel değerleri araştırmacılar tarafından incelenmektedir (Balyan ve ark. 2009). Günümüz futbolunda teknolojik yardımlar futbolu daha da ileri bir noktaya götürmüştür ve başarıya ulaşmak her zamankinden daha önemli hale gelmiştir (İmamoğlu ve ark. 2015). Performansı değerlendirirken futbolu oluşturan birçok parametrenin ayrılıp düzenli bir şekilde incelenerek taktik açıdan da analiz edilmesi gerekmektedir (Göral ve ark. 2012). Yapılan video analiz yöntemlerinin taktik değerlendirmeler açısından birçok avantajı vardır. Gelişmiş yazılım programlarıyla doğrudan veri girişleri yapılarak, istatistiksel analizler değerlendirilebilir. Bu programlar aracılığıyla meydana gelen şut, gol, top kapma gibi tüm spesifik parametrelerin analizleri yapılarak oyunculara tablolar halinde sunulabilmektedir (Pritchard, 2011). Futbolda takım boyu saha içerisinde takım dizilişi bakımından ne kadar kısa olursa futbolcular topun arkasına en kısa sürede geçebilir ve top kazanımı artar, hücuma çıkış saniyesi kısalır böylelikle daha fazla skor üretme ve topa sahip olma şansı yakalayabilir. Örneğin; saha içerisinde 40 metre takım boy ortalaması olan bir takım 60 metre olan takıma göre daha az yorulur ve top sahip olma şansı yakalayabilir. Daha önce yapılan araştırmalarda futbolculara yapılan analiz 
sunumlarının takım performans ve başarı arasında güçlü bir ilişki belirlenmiştir (Sönmeyenmakas 2008). Yapılan analizler antrenörlerin taktik anlayışlarına yardımcı olmakla beraber takımı istenilen düzeye getirmeye yardımcı olmaktadır (Praça, 2019).

Günümüzde 240 milyonu aşkın lisanslı futbolcu bulunmaktadır lisanssız sporcularla birlikte bu sayı milyarları bulmaktadır. Dünyada bu kadar popüler olan futbolun gereksinimlerinin her gün değişmesi kaçınılamazdır. Bir futbol maçının gereksinimleri için futbolcunun fizik kondisyon özellikleri doğru antrenman programlarıyla üst seviyelere taşınabilir (Weineck, 2007). Ancak maçta bir oyuncu ne kadar çalışır? Vücudunda ne gibi değişiklikler olur? Fiziksel ihtiyacı nelerdir ve oyuncu maça hazırlanırken değerleri nasıl olmalıdır. İşte bu sorulara son yıllarda futbol bilimi istatistik yöntemleri ile önemli cevaplar vermiştir gerek takip cihazları gerekse analiz yöntemlerinin kullanımı futbolcuların performanslarının artmasına antrenmanlarla beraber destek vererek arttırılmaya sağlanmaya çalışılmıştır (Bangsbo, 1994). Futbolculara aktarılacak olan doğru analiz yöntemleriyle teknik ve taktik kalite anlayışı yukarılara taşınabilir böylece sporcuların performans durumları da arttırımış olur (Sarmento, 2014). Bu nedenlerle; Bu çalışmanın amacı 2018 FIFA Dünya Kupası Şampiyonu Fransa milli takımının başarı analizinin yapılmasıdır.

\section{Yöntem}

Bu çalışma 2018 FIFA Dünya Kupası Şampiyonu Fransa Milli Takımının farklı değişkenler açısından başarı analizini incelemek amacı ile yapılmıştır. Araştırma verileri WyScout programı üzerinden elde edilmiştir. Müsabakalarda atılan toplam şut, başarılı pas, toplam pas, başarılı pas, ileri pas, başarılı ileri pas, uzun pas, toplam yan pas, korner, kanat hücum yüzdeleri, top hakimiyetleri, takım boyları ve gol yüzdeleri gibi değişkenler analiz edilmiştir. Araştırmada elde edilen tüm veriler SPSS (20.0) programında kaydedilmiştir, frekans ve yüzde değerleri hesaplanarak analiz yapılmıştır.

\section{Bulgular}

Bu çalışmada, 2018 FIFA Dünya Kupası şampiyonunun turnuva performansı farklı değişkenler açısından analiz edilmiştir. Elde edilen bulgular tablolar halinde sunulmuştur. Fransa milli takımının 2018 FIFA Dünya Kupası'nda başarılı şut, 
başarılı pas, korner, serbest vuruş, başarılı ileri pas, başarılı uzun pas, yan pas sayıları ve ortalamaları Tablo 1'de verilmiştir.

Tablo 1. Başarılı Şut, Başarılı Pas, Korner, Serbest Vuruş, Başarılı İleri Pas, Başarılı Uzun Pas, Yan Pas Sayıları Ve Ortalamaları

\begin{tabular}{lcccccc}
\hline Parametreler & $\mathbf{N}$ & Minimum & Maksimum & Ortalama & \multirow{2}{*}{$\%$} \\
\hline Toplam Şut (adet) & 77 & 8 & 18 & 11 & \multirow{2}{*}{37,66} \\
\hline Başarılı Şut (adet) & 29 & 2 & 6 & 4,14 & \\
\hline Toplam Pas (adet) & 2927 & 238 & 655 & 418,14 & \multirow{2}{*}{84,93} \\
\hline Başarılı Pas (adet) & 2486 & 186 & 577 & 355,14 & \\
\hline Toplam İleri Pas (adet) & 1014 & 92 & 195 & 144,86 & \multirow{2}{*}{74,35} \\
\hline Başarılı İleri Pas (adet) & 754 & 63 & 163 & 107,71 & \\
\hline Toplam Uzun Pas (adet) & 501 & 48 & 98 & 71,57 & \multirow{2}{*}{74,85} \\
\hline Uzun Pas (adet) & 375 & 32 & 76 & 53,57 & \multirow{2}{*}{88,36} \\
\hline Toplam Yan Pas (adet) & 980 & 62 & 272 & 140 & \\
\hline Yan Pas (adet) & 866 & 53 & 249 & 123,71 & \\
\hline Korner (adet) & 24 & 0 & 5 & 3,43 & - \\
\hline Serbest Vuruş (adet) & 22 & 1 & 5 & 3,14 & - \\
\hline
\end{tabular}

Dünya Kupası organizasyonu boyunca Fransa Milli takımı rakip kalelere maç başına 77 şut atmış ve bu şutların 29'u (\% 37,66) rakip kalelere isabet etmiştir. Müsabakalarda yapılan toplam 2927 pas girişiminden 2486'sı (\%84,93), 1014 ileri pastan 754'ü (\% 74,35), 501 uzun pastan 375’i (\% 74,85) ve 980 yan pastan 866'sı (\% 88,36) başarılı sonuçlanmıştır. Maç başına 3,43 korner kullanılırken, 3,14 serbest vuruş kullanıldığı belirlenmiştir.

Fransa milli takımının 2018 FIFA Dünya Kupası'nda Top Hâkimiyeti, Sağ ve Sol Kanat Hücum Tehlike Düzeyleri Ortalama değerleri Tablo 2'de verilmiştir.

Tablo 2. Top Hâkimiyeti, Sağ ve Sol Kanat Hücum Tehlike Düzeyleri Ortalama

\begin{tabular}{llll}
\hline Parametreler (\%) & Minimum & Maksimum & Ortalama \\
\hline Top Hâkimiyet & 31 & 64 & 44,57 \\
\hline Sağ Kanat Hücum Tehlike Düzeyi & 0 & 77 & 19,14 \\
\hline Sol Kanat Hücum Tehlike Düzeyi & 0 & 67 & 37,14
\end{tabular}

Dünya Kupası organizasyonu boyunca Fransa Milli takımı oynadığı maçlar boyunca ortalama \% 44,57 topa sahip olma oranı ile oynamıştır. Gerçekleştirdiği tehlikeli hücumlarda \% 19,14 sağ kanadı kullanırken \% 37,14 oranında da sol kanadını kullanmışlardır.

Takımın stoper ve santrafor arasındaki mesafe olarak kabul edilen takım boyu minimum, maksimum ve ortalama değerleri Tablo 3'de verilmiştir.

Tablo 3. Takım Boyu Analizi 


\begin{tabular}{lccc}
\hline Parametre & Minimum & Maksimum & Ortalama \\
\hline Takım Boyu $(\mathrm{m})$ & 33 & 64 & 42,57 \\
\hline
\end{tabular}

Dünya Kupası organizasyonu boyunca Fransa Milli takımı oynadığı maçlar da takım boyu ortalamasının 42,57 metre olduğu görülmüştür. İlk gollerin zaman dilimine göre analizi Tablo 4'de verilmiştir.

Tablo 4. İlk Gollerin Zaman Dilimine Göre Analizi

\begin{tabular}{lcccc}
\hline Zaman Dilimi & $\mathbf{0 - 1 5} \mathbf{~ d k}$ & $\mathbf{1 6 - 3 0} \mathbf{~ d k}$ & $\mathbf{3 1 - 4 5} \mathbf{~ d k}$ & $\mathbf{\%}$ \\
\hline 1. Devre & 1 & 1 & 2 & 66,66 \\
\hline Zaman Dilimi & $\mathbf{4 6 - 6 0} \mathbf{~ d k}$ & $\mathbf{6 1 - 7 5} \mathbf{~ d k}$ & $\mathbf{7 6 - 9 0} \mathbf{~ d k}$ & $\mathbf{\%}$ \\
\hline 2. Devre & 2 & 0 & 0 & 33,34 \\
\hline
\end{tabular}

Dünya Kupası organizasyonu boyunca Fransa Milli takımının oynadığı maçlar da attığı ilk gollerin \% 66,66'sını 1. Devrede atmıştır. Bu gollerin \% 25'ini 0-15 dk arasında, \% 25'ini 16-30 dk arasında ve \% 50'ini 31-45 dakikaları arasında atmıştır. İlk gollerin \% 33,34'ünü 2. devrede atmıştır. Bu gollerin tamamını 46-60 dakikaları arasında atmıştır.

Fransa milli takımının 2018 FIFA Dünya Kupası'nda Futbolcular Arası En Sık Pas Kombinasyonları Tablo 5'de gösterilmiştir.

Tablo 5. Futbolcular Arası En Sık Pas Kombinasyonu

\begin{tabular}{|c|c|c|c|c|}
\hline Maçlar & $\begin{array}{c}\text { Forma } \\
\text { Numaraları }\end{array}$ & $\mathbf{N}$ & Toplam & Ortalama \\
\hline \multirow{2}{*}{ Grup 1.} & 4 & \multirow{2}{*}{23} & \multirow{14}{*}{125} & \multirow{14}{*}{17,86} \\
\hline & 2 & & & \\
\hline \multirow{2}{*}{ Grup 2.} & 13 & \multirow{2}{*}{13} & & \\
\hline & 2 & & & \\
\hline \multirow{2}{*}{ Grup 3.} & 4 & \multirow{2}{*}{30} & & \\
\hline & 19 & & & \\
\hline \multirow{2}{*}{ 2. Tur } & 5 & \multirow{2}{*}{11} & & \\
\hline & 13 & & & \\
\hline \multirow{2}{*}{ Çeyrek Final } & 2 & \multirow{2}{*}{24} & & \\
\hline & 6 & & & \\
\hline \multirow{2}{*}{ Yarı Final } & 2 & \multirow{2}{*}{16} & & \\
\hline & 10 & & & \\
\hline \multirow{2}{*}{ Final } & 6 & \multirow{2}{*}{8} & & \\
\hline & 10 & & & \\
\hline
\end{tabular}


Dünya Kupası organizasyonu boyunca Fransa Milli takımının oynadığı maçlar da futbolcular arasında gerçekleştirilen en sık pas kombinasyonu ortalaması 17,86'dır. Pas kombinasyonunda en aktif futbolcu 2 forma numaralı futbolcudur. En fazla pas kombinasyonu yapan futbolcular 4 ve 19 forma numaralı futbolculardır ve toplam 30 pas yaptıkları görülmektedir.

\section{Tartışma}

Günümüz dünyasında önemli bir yere sahip olan futbol, gerek seyirci gerekse medya üstünlüğü ile endüstri halini almıştır (Zileli, 2017). Bu Çalışmada, 2018 FIFA Dünya Kupasında şampiyon olan Fransa Milli Futbol takımının farklı değişkenler açısından analiz edilmesi amaçlanmıştır. Bu nedenle elit futbolda sporculardan en yüksek verimi almak futbolun vazgeçilmez gerçeğidir (Gürkan ve ark. 2016). İlerleyen teknoloji ile beraber sporculardan en yüksek verimi almak daha kolay hale gelmiştir, 90 dakikalık bir oyunu hafızada tutmak ve sporcunun performansını objektif olarak değerlendirebilmek için son yıllarda bilgisayar-video analiz yöntemleri ortaya çıkmıştır ve bu yöntemlerle oyunun her anı ve sporcunun her parametresi doğru şekilde kaydedilip üzerinde çalışma yapılma imkanı sağlamaktadır (Franks ve ark. 2016).

Analiz yöntemlerinin futbolculara doğru aktarılarak geri bildirimler alınmasının futbolda başarıya etki ettiği düşünülmektedir ve yapılan çalışmalarda bu etkiler üzerine odaklanılmıştır. Literatüre bakıldığın da analiz çalışmalarına rastlamak mümkündür. Yapılan bu çalışmada da Rusya'da düzenlenen 2018 FIFA Dünya Kupası şampiyonu Fransa Milli Takımını şampiyonluğa götüren başarı parametrelerinin incelenmesi amaçlanmıştır.

2018 FIFA Dünya Kupasında şampiyonu Fransa Milli Takımının turnuva boyunca rakip kalelere 77 şut atmış ve bu şutların 29'u (\% 37,66) rakip kalelere isabet etmiştir. Fransa milli takımının maç başı şut ortalaması ise \%11'dir. Göral'ın (2015) yaptığı çalışmada 2014 FIFA Dünya Kupasında şampiyon olan Almanya Milli futbol takımının maç başına 13,9 şut atıp ve bu şutların 10,1'nin (\% 73,2) isabet ettiğini bildirmiştir. Gürkan ve ark. (2016) yılında yapmış olduğu 2016 Avrupa futbol şampiyonasındaki müsabakaların teknik analizi adlı çalışmasında kazanan takımların şut maç başı şut ortalamasını 13,40 olarak bulmuştur. Araya ve ark. (2013) yılında İngiltere Premier Ligi' nde ilk 10 ve son 10 takımın başarı analizini inceledikleri çalışmalarında ilk 10 içinde yer alan takımların maç başına ortalama 15,7l'lik bir şut 
oranıyla maçları tamamladıklarını tespit etmiştir. Arıkan (2009) yılında yapmış olduğu yüksek lisans tezinde 2006 Dünya Kupasında çeyrek final, yarı final ve final oynayan takımların hücum organizasyonlarını incelemiştir ve Fransa Milli takımının final maçında toplam 15 şut çekerek bunlardan 3 tanesinde isabet sağlamıştır. yılında Ballesteros ve ark. (2010) İspanya liginde yapmış oldukları çalışmada ise ilk 4 sıradaki takımın şut yüzdelerini 16.25 olarak bulmuşlardır. Bu çalışmada ise Fransa Milli takımının sonuçlarına bakıldığında takımının şut yüzdesinin \%37.66 olduğu bulunmuştur ve diğer çalışmalarda ki bulgularla benzerlikler göstermektedir.

Fransa Milli takımının turnuva boyunca müsabakalarda yapılan toplam 2927 pas girişiminden 2486'sı (\%84,93), 1014 ileri pastan 754'ü (\% 74,35), 501 uzun pastan 375'i (\% 74,85) ve 980 yan pastan 866'sı (\% 88,36) başarılı sonuçlanmıştır. Göral (2015) 2014 Dünya Kupasındaki başarılı takımları incelediği çalışmasında Almanya milli takımının 4990, Arjantin takımının 4275, Hollanda takımının 3884 ve Brezilya takımının 3953 pas girişimi olduğunu tespit etmiştir ve bu pas girişimlerden 4087 pas isabetiyle şampiyon Almanya Milli takımı olmuştur. Şampiyonlar Ligi'nde kazanan ve kaybeden takımların başarı performanslarının incelendiği çalışmada yarı finalde kazanan takımların en iyi pas yapan takımı olarak maç ortalaması 469 pastır (Penas, 2011). Türkiye Süper Lig'inde, Gürkan (2018) tarafından iç sahada ve dış sahada oynayan takımların avantajlarını analiz etmek için yaptığı çalışmada başarılı pas sayılarını maç başına iç sahada 312 dış sahada 299 olarak bulmuştur. Veriler incelendiğinde diğer çalışmalarda takımların daha fazla pas yaptıkları görülse de pasların isabet oranlarının Fransa Milli Takımına göre daha düşük olduğu görülmüştür

Dünya Kupası organizasyonu boyunca Fransa Milli Takımı oynadığı maçlar boyunca ortalama \% 44,57 topa sahip olma oranı ile oynamıştır. Parziale ve Yates (2013) İngiltere Premier Liginde futbolda topa sahip olmanın değeri üzerine yaptıkları bir çalışmada, bir takım \%64'den daha fazla topa sahip olma yüzdesine sahip olduğunda, maçı kazanma ve topa sahip olma yüzdesi arasında pozitif yönde anlamlı bir ilişki bulmuşlardır. Lago ve Marti'nin (2007) İspanya Laliga'da (futbol ligi) yaptıkları çalışmada futbolda topa sahip olmanın belirleyicilerini incelemek amacıyla yaptıkları çalışmada, takımların topa sahip olma yüzdelerinin galibiyetle ya da beraberlikle biten maçlarda mağlup olarak ayrıldıkları maçlardakinden daha yüksek olduğunu tespit etmişlerdir. Castellano, Casamichana ve Lago (2012) yaptıkları çalışmada, 2002, 
2006 ve 2010 Dünya Kupalarında maçları kazanan takımların topa sahip olma yüzdelerini \%51.6 \pm 6.8 olarak bulurlarken, kazanan takımların topa sahip olma yüzdeleri ile kaybeden ve berabere kalan takımlar arasında $p<0,01$ düzeyinde anlamlı fark bulmuşlardır. Araya ve Larkin'in (2013) İngiltere Premier Liginde ilk on sırada ve son on sırada yer alan takımlar arasındaki farklılıkları inceledikleri çalışmalarında, ilk on sırada yer alan takımların topa sahip olma yüzdesi

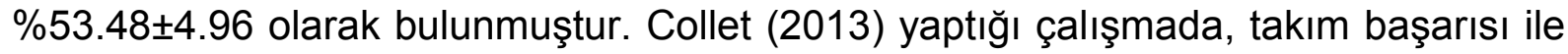
şut atma ve pas yapma arasında önemli bir ilişki bulunduğunu, bunun yanında takımların daha fazla topa sahip olması ile şut atma, gol üretme ve başarılı pas yapma sayıları arasında güçlü bir bağlantı olduğunu vurgulamaktadır. Bradley ve ark. (2013) yaptıkları çalışmada, İngiltere Premier Liginde topa sahip olma yüzdesi yüksek olan takımların başarılı pas yüzdelerinin $\% 80.8 \pm 10.3$ ile topa sahip olma yüzdesi düşük takımlardan (\%74.7\$12.8) oldukça yüksek olduğunu saptamışlardır. Almanya Milli takımının 2014 Dünya Kupasını kazanırken \%56.71 gibi yüksek topa sahip olma yüzdesine ve \%81.9 gibi çok yüksek başarılı pas oranına sahip olması başarılı performansının temel belirleyicilerinden birkaçı olarak söylenebilir. Yukarıdaki çalışmalar incelendiğinde genel olarak topa sahip olma yüzdesiyle futbolda başarı arasında bir korelasyon olduğu belirtilmektedir. Fakat çalışmamızın sonuçları incelendiğinde Fransa milli futbol takımının topa sahip olma yüzdesi ortalamasının düşük olduğu görülmüştür. Tek başına topa sahip olma yüzdesinin futbolda başarılı olmak için yeterli bir parametre olmadığı düşünülmektedir.

Dünya Kupası organizasyonu boyunca Fransa Milli takımının oynadığı maçlar da attığı ilk gollerin \% 66,66'sını 1. Devrede atmıştır. Bu gollerin \% 25'ini 0-15 dk arasında, \% 25'ini 16-30 dk arasında ve \% 50'ini 31-45 dakikaları arasında atmıştır. İlk gollerin \% 33,34'ünü 2. devrede atmıştır. Bu gollerin tamamını 46-60 dakikaları arasında atmıştır. Michailidis, ve ark. (2013) göre, atılan goller, spor oyunlarında ve turnuva gibi organizasyonlarda, takımların başarılı olması ve iyi bir analiz yapılabilmesi için anahtar bir rol teşkil etmektedir. Fransa milli futbol takımı ilk gollerini genellikle 1. devrede atmıştır. Bu durum maç üstünlüğü olarak maçın sonuna kadar üstünlük kurmalarının ve başarıya ulaşmalarında etkili olduğu düşünülmektedir.

Gerçekleştirdiği tehlikeli hücumlarda \% 19,14 sağ kanadı kullanırken \% 37,14 oranında da sol kanadını kullanmıştır. Fransa milli futbol takımı gerçekleştirdiği tehlikeli hücumlarda genellikle sağ kanadını kullandığı söylenebilir. Yapılan 
çalışmalara bakıldığında futbolda kanat organizasyonlarının sonuca etkisi veya tehlikeli pozisyon yaratma konusunda literatüre rastlanmamıştır, bu çalışmada kanat organizasyonlarının tehlike yaratma durumuna bakıldığında şampiyonluğa etkisi olduğu söylenebilir. Çalışma ileri ki çalışmalarda kullanılmak üzere kanat incelemesi bakımından literatüre katkıda bulunacağı düşünülmektedir.

Dünya Kupası organizasyonu boyunca Fransa Milli takımının oynadığı maçlar da futbolcular arasında gerçekleştirilen en sık pas kombinasyonu ortalaması 17,86 'dır. Pas kombinasyonun da en aktif futbolcu 2 forma numarasıyla oynayan sağ bek futbolcusudur. En fazla pas kombinasyonu yapan futbolcular 4 numaralı defans oyuncusu ile 19 forma numaralı defans oyuncusudur ve grubun ilk maçı olan Danimarka maçında toplam 30 pas yapmışlardır. Pas kombinasyonlarının sayısı rakibin zorluk derecesi ve teknik taktik anlayışla paralel olarak maçlarda farklılık gösterdiği düşünülmektedir. En çok pas kombinasyonun da bulunduğu görülen 2 forma numaralı sağ bek oyuncusunun öne çıkmasının sebebi olarak mevki sporcunun teknik özellikleri ve takımın teknik taktik anlayışıyla alakalı olduğu düşünülmektedir. Yine pas kombinasyonun da bulunan oyuncular incelendiğinde benzerlikler görülmektedir. Literatür tarandığında pas kombinasyonlarının sonuca katkısı ile olarak çalışmaya rastlanmamıştır. Bu çalışma pas kombinasyonu nedeniyle ileri de yapılacak olan çalışmalar için katkı sağlayacağı düşünülmektedir.

\section{Sonuç}

Sonuç olarak; 2018 FiFA Dünya Kupasında şampiyon olan Fransa milli takımının verileri incelendiğinde literatürdeki çalışmalara nazaran daha düşük futbol istatistiklerine sahip olmasına rağmen daha başarılı bir performans ortaya koydukları görülmüştür. Bu durumun sebebinin Fransa milli takımının teknik ve taktik anlayışındaki disiplin olduğu düşünülmektedir. Bununla beraber kadrosunda bulunan futbolcuların bireysel performanslarının da bu sonuçların ortaya çıkmasında etkili olduğu söylenebilir.

\section{Kaynakça}

Araya J., Larkin P. (2014). Key Performance Variables Between the Top 10 and Bottom 10 Teams in the English Premier League 2012/2013 Season. Uni of Sydney Papers. 17-29. 
Arıkan, İ. (2009). Fifa 2006 Dünya Kupasında Çeyrek Final, Yarı Final ve Final Oynayan Futbol Takımlarının Hücum Organizasyonlarının İncelenmesi ve Maç Sonuna Etkisi. Yüksek Lisans Tezi. Ege Üniversitesi Sağlık bilimleri Ensititüsü. Hareket ve Antrenman Anabilim Dalı.

Balyan M., Vural F., Arıkan N., Tunçer Y. (2009). Farklı Saha Boyutlarında Oynanan U-13 U-14 Futbol Müsabakalarının Bazı Teknik ve Taktik Verilerinin İncelenmesi. 3. Ulusal Futbol Bilim Kongresi.

Bangsbo J. (1994). Futbolda Fizik Kondisyon Antrenmanı. Ho+Storm Basvaerd. Danimarka. 11-12.

Baskaya G., Senturk A. (2017): Performance Analysis of 2015 Fifa Women's World Cup Champion USA National Team. Turkish Journal Sport and Exercise. 19(2): 196-201.

Bradley, P.S., Lago-Penas, C., Rey, E., Diaz, A.G. (2013) The effect of high and low percentage ball possession on physical and technical profiles in English FA Premier League soccer matches. Journal of Sports Sciences. 31(12): 12611270.

Castellano, J., Casamıchana, D. \& Lago, C. (2012). The use of match statistics that discriminate between successful and unsuccessful soccer teams. Journal of Human Kinetics. 31: 139-147.

Cerrah A.O, Yüksel Y, Taşçıŏlu R. (2016). 2015-2016 Sezonu Spor Toto Süper Lig Takımlarının Maç Analizi Sonuçlarının Karşılaştıııması. Uluslararası Hakemli Akademik Spor Sağlık ve Tıp Bilimleri Dergisi. 21:1-15.

Collet, C. (2013). The possession game? A comparative analysis of ball retention and team success in European and international football, 2007-2010. Journal of Sports Sciences. 31(2): 123-136.

Franks IM., Hughes M. (2016). Successful Coaching Through Match Analysis. Meyer and Meyer Sport. Ind Ed.

Göral K. (2015). 2014 Fifa Dünya Kupasının Başarııı Takımlarında Pas Başarı Yüzdeleri ve Topa Sahip Olma Oranları. International Journal of Science Culture and Sport. 3(1): 86-95.

Göral K., Saygın Ö. (2012). Birinci Ligde Yer Alan Bir Futbol Takımının Sezon Performansının İncelenmesi. Uluslararası İnsan Bilimleri Dergisi. 9(2): 10181031. 
Göral, K. (2015). Performance analysis of the last champion German National Team in 2014 FIFA World Cup Son şampiyon Alman Milli Takımının 2014 FIFA Dünya Kupası performansının analizi. Journal of Human Sciences, 12(1), 1107-1117.

Gürkan O. (2018). İç Saha Deplasmanda Oynanan Müsabakaların Bazı Performans Paramatereleri Açısından Karşılaştırılması: Türkiye Futbol Süper Ligi Örneği. Akademik Sosyal Araştırmalar Dergisi. 6(76): 442-448.

Gürkan O., Müniroğlu S. (2016). 2016 Avrupa Futbol Şampiyonasındaki Müsabakaların Teknik-Taktik Açıdan Analizi. Spormetre Dergisi. 16(3): 101108.

İmamoğlu R., Bostancı M., İmamoğlu M. (2015). 2012-2013 Türkiye Spor Toto Süper Liginde Mücadele Eden Takımların Yaptıkları Maç Sonuçlarının Farklı Parametrelere Göre İncelenmesi. International Journal of Science Culture and Sport. 1(4): 159-166.

İnce T, Önder T. The Effect of Plyometric Training Program on Sportive Performance Parameters in Young Soccer Players. (2018). Turkish Journal of Sport and Exercise. 20(2): 184-190.

Lago, C., \& Martin, R. (2007). Determinants of possession of the ball in soccer. Journal of Sports Sciences. 25(9): 969-974.

Michailidis C, Michailidis Y, Mitrotasios M, Papanikolaou Z. (2013). Analysis of goals scored in the UEFA Champions League in the period 2009-2010. Serbian Journal of Sports Sciences, 7(2): 51-55.

Michailidis, C., Michailidis, Y., Mitrotasios, M., \& Papanikolaou, Z. (2013). Analysis of goals scored in the uefa champions league in the period 2009/2010. Serbian Journal of Sports Sciences. 7(2): 51-55.

Parziale, E.J., \& Yates, P.A. (2013). Keep the Ball! The Value of Ball Possession in Soccer. Reinvention: an International Journal of Undergraduate Research. 6(1): 1-24.

Penas C., Dellal A. (2010). Ball Possesion Strategies in Elite Soccer According to the Evolution of the Match-Score the Influence of Situational Variables. Journal of Human Kinetics. 25:93-100.

Praça G.M., Lima B.B., Bredt G.S.T., Sousa B.R., Clemente M.F., Andrade A.G. (2019). Influence of Match Status on Players Prominence and Teams Network 
Properties During 2018 Fifa World Cup. Frontiers in Psychology. (10): 695700.

Sarmento H, Marcelino R, Anguera T, Campaniço J, Matos N, Leitao AC (2014). Match analysis in football: A systematic review. Journal of Sports Sciences. 33(20):1831-1843.

Sönmeyenmakas A. (2008). Uefa Şampiyonlar Liginde Atılan Gollerin Analizi. Trakya Üniversitesi Sağlık Bilimleri Enstitüsü Yüksek Lisans Tezi. 3-5.

Yüksel Y., Taşçıoğlu R., Cerrah O.A. (2017). Avrupa Futbol Liglerinin Üçüncü Bölge Hücum Organizasyonlarının Analizi. Uluslararası Multidisipliner Akademik Araştırmalar Kongresi. 4(2): 48-58.

Zileli R., Söyler M., Genç A. (2017). 2016-2017 Turkcell Süper Liginde Oynanan Maçlarda Kullanılan Köşe Vuruşlarının Maç Analizi. İnönü Üniversitesi Beden Eğitimi ve Spor Bilimleri Dergisi. 4(3): 48-58.

Weineck J. (2007). Training Performance Physiology Oriented Exercise Testing and Prescription With Particular Consideration of Training for Children and Adolescents. Spitta Balingen. Almanya. 72-74. 